\title{
Influence of adsorption and anaerobic granular sludge characteristics on long chain fatty acids inhibition process
}

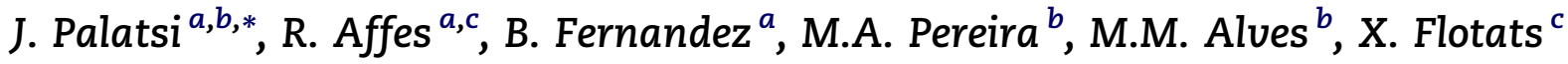 \\ ${ }^{a}$ IRTA, GIRO Joint Research Unit IRTA-UPC, Torre Marimon, E-08140 Caldes de Montbui, Barcelona, Spain \\ ${ }^{\mathrm{b}}$ IBB - Institute for Biotechnology and Bioengineering, Centre of Biological Engineering, University of Minho, Campus de Gualtar, \\ 4710-57 Braga, Portugal \\ ${ }^{c}$ Dept. of Agrifood Engineering and Biotechnology, Universitat Politècnica de Catalunya (UPC), Parc Mediterrani de la Tecnologia, Edifici D-4, \\ E-08860 Castelldefels, Barcelona, Spain
}

\section{A R T I C L E I N F O}

Article history:

Received 11 May 2012

Received in revised form

4 July 2012

Accepted 6 July 2012

Available online 16 July 2012

Keywords:

Anaerobic granular sludge

LCFA inhibition

Adsorption isotherms

16S rDNA profiling

Microscopic techniques

\begin{abstract}
A B S T R A C T
The impact of LCFA adsorption on the methanogenic activity was evaluated in batch assays for two anaerobic granular sludges in the presence and absence of bentonite as synthetic adsorbent. A clear inhibitory effect at an oleate (C18:1) concentration of $0.5 g_{\mathrm{C} 18: 1} \mathrm{~L}^{-1}$ was observed for both sludges. Palmitate (C16:0) was confirmed to be the main intermediate of C18:1 degradation in not adapted sludge and its accumulation was further evidenced by fluorescence staining and microscopy techniques. LCFA inhibition could be decreased by the addition of bentonite, reducing the lag-phase and accelerating the kinetics of LCFA degradation, concluding in the importance of the adsorptive nature of the LCFA inhibitory process. Granule morphology and molecular profiling of predominant microorganisms revealed that biomass adaptation to LCFA could modify the intermediates accumulation profiles and process rates.
\end{abstract}

(c) 2012 Elsevier Ltd. All rights reserved.

\section{Introduction}

Anaerobic digestion is a highly sustainable waste treatment process because it combines organic matter removal with energy production in the form of biogas. The energy yield depends, among other factors, on the organic matter composition (generally defined as the ratio between lipids-proteins-carbohydrates). In particular, lipids are interesting substrates for the anaerobic digestion process due to the high potential methane yield. Under anaerobic conditions, lipids are initially hydrolyzed to glycerol and long chain fatty acids (LCFA), which are further converted by acetogenic bacteria ( $\beta$-oxidation process) to hydrogen $\left(\mathrm{H}_{2}\right)$ and acetate (Ac), and finally to methane $\left(\mathrm{CH}_{4}\right)$ by methanogenic archaea.

LCFAs are the main intermediate by-product of the lipid degradation process, and their accumulation in anaerobic digesters has been related with problems of sludge flotation, biomass washout and inhibition of the microbial activity (Rinzema et al., 1994). These LCFA inhibitory effects have been associated to the interference with the electron transport chain, impairment of the nutrient uptake, inhibition of specific enzyme activities, or to the generation of toxic peroxidation and autooxidation products (Desbois and Smith, 2010). It has long been stated that adsorption of LCFA onto the cell membrane is the main factor determining its

\footnotetext{
* Corresponding author. IRTA, GIRO Joint Research Unit IRTA-UPC, Torre Marimon, E-08140 Caldes de Montbui, Barcelona, Spain. Tel.: +34 938654350; fax: +34 938650954.

E-mail address: jordi.palatsi@irta.cat (J. Palatsi).

0043-1354/\$ - see front matter @ 2012 Elsevier Ltd. All rights reserved.

http://dx.doi.org/10.1016/j.watres.2012.07.008
} 
biological toxicity (Galbraith and Miller, 1973). More recently, Pereira et al. (2005) evidenced the importance of LCFA on transport limitations at the level of the cell membrane, and on how this affects the overall anaerobic digestion process. The fact that LCFA inhibition is reversible suggests that it is partially driven by LCFA adsorption onto the biomass and that the methanogenic activity might thus be resumed once the LCFA that have been accumulated onto the biomass are progressively metabolized.

Oleate (C18:1), stearate (C18:0) and palmitate (C16:0) are the major constituents in lipid-rich wastes and wastewaters (Battimelli et al., 2010; Valladão et al., 2011). The inhibitory effect of a specific LCFA has been defined as concentration dependent, but it is also related to the LCFA chain length and degree of saturation (Lalman and Bagley, 2001). Differences on cell membrane properties between bacteria and archaea also play an important role on LCFA toxicity (Zheng et al., 2005). C16:0 has been proposed to be the main intermediate and the key inhibitory specie during the anaerobic degradation of C18:1 via the $\beta$-oxidation process (Pereira et al., 2002). Recently, several studies have published valuable information dealing with the diversity of saturated/unsaturated LCFA degraders and syntrophic methanogens interactions (Sousa et al., 2007).

Different strategies have been studied to prevent or to recover lipid/LCFA inhibited systems. The solubilization of lipid waste via saponification (Battimelli et al., 2010) or enzymatic pre-treatments (Valladão et al., 2011), the application of feeding procedures based on sequential LCFA accumulationdegradation steps (Cavaleiro et al., 2009), the addition of easily degradable co-substrates (Kuang et al., 2006) or the addition of adsorbents as recovery agents (Palatsi et al., 2009) have been proposed as possible strategies to limit the inhibitory effects.

Despite the extensive literature references about LCFA inhibition, only few studies focus on how important the adsorption process during the LCFA degradation is (Hwu et al., 1998; Pereira et al., 2005). The aim of the present study is to monitor the LCFA adsorption over granular sludge and to evaluate its impact on process inhibition, by means of: specific batch tests (monitoring LCFA evolution), addition of synthetic adsorbents (bentonite), molecular profiling of the predominant microorganisms and fluorescence staining microscopy imaging.

\section{Material and methods}

\subsection{Physicochemical and biological characterization of biomass}

Two different anaerobic granular sludges were used in present experiments, sampled from industrial beverage wastewater UASB reactors: sludge-A from a beer brewery (A Coruña, Spain) and sludge-B from a fruit juice processing industry (Lleida, Spain). Both sludges were characterized in terms of granular morphology, methanogenic activity and bacterial community structure.

The characterization of the granular morphology of both sludges (20 samples, containing more than 1200 granules per sample or $>0.2$ g per sample) was performed analyzing digitalized images (768 $\times 574$ pixel size, 256 grey levels) with the Analyze Particle Tool of ImageJ package software (National Institutes of Health, USA). Images were binarized and particles sizes were evaluated by equivalent diameter and specific surface $\left(\mathrm{cm}^{2} \mathrm{~g}^{-1} \mathrm{vss}\right)$, calculated from the particles projected area, according to Pereira et al. (2003).

Methanogenic activity tests (SMA) of both sludges on acetate $(\mathrm{Ac})$ and hydrogen $\left(\mathrm{H}_{2} / \mathrm{CO}_{2}\right)$ were performed in batch anaerobic vials $(120 \mathrm{~mL}$ total volume vials with $50 \mathrm{~mL}$ of media working volume) at mesophilic temperature $\left(35^{\circ} \mathrm{C}\right)$, as described by Angelidaki et al. (2009).

The original microbial community structure was depicted by molecular profiling. The total DNA of biomass samples of both sludges was extracted and bacterial 16S rDNA gene fragments were amplified by polymerase chain reaction procedure (PCR). Amplicons were subsequently resolved by denaturing gradient gel electrophoresis (DGGE) analysis. Relevant DGGE bands were excised, reamplified by PCR and sequenced as described in Palatsi et al. (2010). Sequences were edited using the BioEdit software package v.7.0.9 (Ibis Biosciences, USA), compared against the NCBI genomic database with the BLAST search alignment tool (Altschul et al., 1990), and related to phylogenetic groups by using the RDP Naive Bayesian Classifier (Wang et al., 2007). Obtained nucleotide sequences have been deposited in the GenBank database under accession numbers HM100129-HM100135.

\subsection{LCFA adsorption isotherms on bentonite and granular sludge}

The adsorption isotherms for oleate on bentonite and on anaerobic granular biomass (sludge-A) were determined in batch experiments $(1 \mathrm{~L}$ vials with $500 \mathrm{~mL}$ of media working volume). Media was composed by demineralized water, sodium bicarbonate ( $1 \mathrm{~g}_{\mathrm{NaHCO}_{3}} \mathrm{~g}^{-1}$ CoDadded) and bentonite or inactivated anaerobic granular sludge as sorbents. In order to differentiate LCFA adsorption from biological degradation, biomass was previously inactivated by incubation $\left(2 \mathrm{~h}\right.$ at $\left.4{ }^{\circ} \mathrm{C}\right)$ with formaldehyde solution $(4 \% \mathrm{v} / \mathrm{v})$. This protocol was selected to minimize cell wall damage produced by other protocols (Ning et al., 1996). Sodium oleate at a concentration range from 0.5 to $5.5 \mathrm{~g}_{\mathrm{C} 18: 1} \mathrm{~L}^{-1}$ was added as LCFA sorbate model. Vials were maintained at mesophilic $\left(35^{\circ} \mathrm{C}\right)$ anaerobic conditions under continuous shaking (150 rpm).

Liquid samples were withdrawn periodically from the vials to monitor the soluble C18:1 concentration (C;

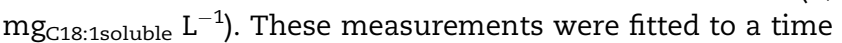
course asymptotical exponential decay curve $\left(C=C e+\alpha e^{-\beta t}\right)$ to determine the equilibrium $\mathrm{C} 18: 1$ concentration in the liquid phase $\left(\mathrm{Ce} ; \mathrm{mg}_{\mathrm{C} 18: 1 \text { soluble }} \mathrm{L}^{-1}\right)$. Obtained Ce values, for each tested concentration, were used to fit a Langmuir isotherm model (Eq. (1)):

$C_{\text {ad }}=\frac{C_{\max } K C_{e}}{1+K C_{e}}$

where $C_{a d}$ is the equilibrium amount of sorbate per unit of sorbent ( $\mathrm{mg}_{\mathrm{C} 18: 1 a d s o r b e d} \mathrm{~g}^{-1}$ TSadsorbent), $\mathrm{C}_{\max }$ is the maximum sorptivity of $\mathrm{C} 18: 1$ on sorbent $\left(\mathrm{mg}_{\mathrm{C} 18: 1 \text { adsorbed }} \mathrm{g}^{-1}\right.$ TSadsorbent) and $\mathrm{K}$ is the Langmuir equilibrium constant ( $\mathrm{L} \mathrm{mg}^{-1}$ C18:1soluble). 
Sorbent concentrations were expressed in total solids (TS) units to compare biomass and bentonite adsorption capacity.

\subsection{Selection of LCFA inhibitory concentration}

The inhibitory effect of LCFA over anaerobic granular sludges (sludge-A and sludge-B) was assessed in batch assays. Increasing concentrations of C18:1 from 0.1 to $1.5 \mathrm{~g}_{\mathrm{C} 18: 1 \mathrm{~L}^{-1}}$ were tested in $120 \mathrm{~mL}$ glass vials $(50 \mathrm{~mL}$ of working volume) containing $5 \mathrm{gvss} \mathrm{L}^{-1}$ of granular sludge and $1 \mathrm{~g}_{\mathrm{NaHCO}_{3}} \mathrm{~g}^{-1}$ CoDadded, under strict mesophilic $\left(35^{\circ} \mathrm{C}\right)$ anaerobic conditions and continuous shaking (150 rpm). Those tests were carried out to determinate the amount of C18:1 that causes a clear and long lasting inhibition on biogas production over the selected inoculum. Specific methane rates were determined by the initial slope of the accumulated $\mathrm{CH}_{4}$ production curve per biomass content unit $\left(\mathrm{mL}_{\mathrm{CH}_{4}} \mathrm{~g}^{-1} \mathrm{vss}^{-1}\right)$, to better compare different sludges responses.

\subsection{Influence of the adsorptive process over LCFA inhibition}

Three different experiments with bentonite addition were tested in batch assays in order to evaluate and quantify the effect of the LCFA-adsorption over LCFA inhibitory process. Main experimental set-up, including timing for sludge exhaustion, methanogenic activation and oleate or bentonite addition was summarized in Table 1.

The first experiment (E1) was performed with sludge-A (Ta_1 vials in Table 1) and consisted in testing the possibility of prevention granular sludge inhibition by means of a preliminary bentonite addition into vials (day -2 ), prior the LCFA inhibitory pulse (day +1$)$. Contrary, the second experiment (E2), also performed with sludge-A (Ta_2 vials in Table 1), was focused on testing the possibility of recovery the degradation capacity of inhibited granular sludge (LCFA pulse in day +1 ) by means of bentonite post-addition (day +2$)$. As sludge-A was sampled months before the present experiments (stored at $4{ }^{\circ} \mathrm{C}$ ), a biomass activation step with an acetate pulse (day 0 , in Table 1) was included in E1 and E2 experiments to check the sludge methanogenic activity.

The third experiment (E3) was performed with sludge-B ( $\mathrm{Tb}$ vials in Table 1) and was intended to capture LCFAs by incubating a higher concentration of bentonite with oleate (day-4), to force exclusively the LCFA adsorption over bentonite, prior to vials inoculation with granular sludge (day 0 ). Since sludge$\mathrm{B}$ arises from a steady state large-scale reactor, and was sampled immediately before the present assay, the sludge was previously exhausted (day-2) but the activation step with acetate was omitted.

In all experiments (Table 1), vials were previously buffered $\left(3 \mathrm{~g}_{\mathrm{NaHCO}_{3}} \mathrm{~L}^{-1}\right)$ and the initial biomass and oleate concentrations were set constants $\left(5 \mathrm{gvss} \mathrm{L}^{-1}\right.$ and $0.5 \mathrm{~g}_{\mathrm{C} 18: 1} \mathrm{~L}^{-1}$, respectively). Control vials ( $\mathrm{Ca}$ and $\mathrm{Cb}$ ), with LCFA and biomass but without bentonite, and blank vials (BLa and BLb) with only biomass, were also run for all the experiments (Table 1). Incubations were carried out at $35^{\circ} \mathrm{C}$ under shaking (150 rpm) and anaerobic conditions. Each treatment was performed in triplicate for biogas analysis $\left(\mathrm{CH}_{4}\right)$, and 12 vials per treatment were withdrawn during incubations in order to determine long chain fatty acids present in the solid and liquid phase (LCFA $A_{S}$ and $L_{C F A}$, respectively), and the volatile fatty acids (VFA) profile. All parameters were expressed in COD units to better follow the mass balance.

To quantify the adsorption effect of bentonita addition, a Gompertz equation (Eq. (2)) was fitted to the methane production profiles in E2 experiments:

$P=P_{\max } \cdot \exp \left[-\exp \left(\frac{r_{m} \cdot e}{P_{\max } \cdot(t-\lambda)+1}\right)\right]$

where $P$ is the accumulated methane production $\left(\mathrm{mg} \mathrm{COD} \mathrm{CH}_{4} \mathrm{~L}^{-1}\right.$ ), which is expressed as a time $t$ function (day), $P_{\text {max }}$ is the methane production potential $\left(m g \mathrm{COD}_{\mathrm{CH}_{4}} \mathrm{~L}^{-1}\right), r_{m}$ is the maximum methane production rate (mg COD $\mathrm{CH}_{4} \mathrm{~L}^{-1}$ day $^{-1}$ ) and $\lambda$ is the lag phase period on biogas production (day).

\subsection{Microscopy observations}

For microscopy observation, intermediate (day +10$)$ samples of granular sludge-A vials (Table 1), free (BLa) and submitted to LCFA pulse ( $\mathrm{Ca}$ ), were fixated ( $4 \% \mathrm{v} / \mathrm{v}$ formaldehyde in PBS) and embedded in Tissue-Tek OCT (optimal cutting temperature) compound (Sakura Finetek), as described in Batstone et al. (2004). Granule sections of $10 \mu \mathrm{m}$ were obtained with a cryostat (CM 1900 Leica, Germany), operated with a knife temperature of $-20^{\circ} \mathrm{C}$ and a cabinet temperature of $-18{ }^{\circ} \mathrm{C}$. Slides were stained with multiple fluorochrome dyes. DAPI

Table 1 - Experimental set-up of batch experiments to evaluate LCFA adsorption effect.

\begin{tabular}{|c|c|c|c|c|}
\hline Experiment E1 and E & Day -2 (sludge exhaustion) & Day 0 (activation) & Day +1 (inhibition) & Day +2 (recovery) \\
\hline Ta_1 (E1) & $0.5 g_{\text {Bentonite }} \mathrm{L}^{-1}+5 \mathrm{gvsS}_{\mathrm{VA})} \mathrm{L}^{-1}+3 \mathrm{~g}_{\mathrm{NaHCO}_{3}} \mathrm{~L}^{-1}$ & $+30 \mathrm{mM}_{\mathrm{Ac}}$ & $+0.5 g_{C 18: 1} L^{-1}$ & - \\
\hline Ta_2 (E2) & $5 \mathrm{gvss}_{(\mathrm{A})} \mathrm{L}^{-1}+3 \mathrm{~g}_{\mathrm{NaHCO}_{3}} \mathrm{~L}^{-1}$ & $+30 \mathrm{mM}_{\mathrm{Ac}}$ & $+0.5 g_{\mathrm{C} 18: 1} \mathrm{~L}^{-1}$ & +0.5 gentonite $\mathrm{L}^{-1}$ \\
\hline $\mathrm{Ca}$ & $5 \mathrm{gvSS}_{\mathrm{A}(\mathrm{A})} \mathrm{L}^{-1}+3 \mathrm{~g}_{\mathrm{NaHCO}_{3}} \mathrm{~L}^{-1}$ & $+30 \mathrm{mM}_{\mathrm{Ac}}$ & $+0.5 \mathrm{~g}_{\mathrm{C} 18: 1} \mathrm{~L}^{-1}$ & - \\
\hline BLa & $5 \mathrm{gVSS}_{(\mathrm{A})} \mathrm{L}^{-1}+3 \mathrm{~g}_{\mathrm{NaHCO}_{3}} \mathrm{~L}^{-1}$ & $+30 \mathrm{mM}_{\mathrm{Ac}}$ & - & - \\
\hline Experiment E3 & Day -4 (LCFA-bentonite adsorption) & \multicolumn{2}{|c|}{ Day -2 (sludge exhaustion) } & Day 0 (inoculation) \\
\hline $\mathrm{Tb}(\mathrm{E} 3)$ & $5.0 g_{\text {Bentonite }} \mathrm{L}^{-1}+0.5 \mathrm{~g}_{\mathrm{C} 18: 1} \mathrm{~L}^{-1}+3 \mathrm{~g}_{\mathrm{NaHCO}_{3}} \mathrm{~L}^{-1}$ & \multirow{3}{*}{\multicolumn{2}{|c|}{$0.5 \mathrm{~L}_{\text {sludge B }}$ under anaerobic conditions }} & $+5 \mathrm{gvss}_{(\mathrm{B})} \mathrm{L}^{-1}$ \\
\hline $\mathrm{Cb}$ & $0.5 \mathrm{~g}_{\mathrm{C} 18: 1} \mathrm{~L}^{-1}+3 \mathrm{~g}_{\mathrm{NaHCO}_{3}} \mathrm{~L}^{-1}$ & & & $+5 \operatorname{gvsS}(\mathrm{B}) \mathrm{L}^{-1}$ \\
\hline BLb & $3 \mathrm{~g}_{\mathrm{NaHCO}_{3}} \mathrm{~L}^{-1}$ & & & $+5 \operatorname{gvss}_{(\mathrm{B})} \mathrm{L}^{-1}$ \\
\hline
\end{tabular}


(4,6-diamidino-2-phenylindole, Sigma) was used as probe for biomass or total cells, while Nile Red (9-diethylamino-5Hbenzo[ $\alpha]$ phenoxazine-5-one, Sigma) was selected as probe for hydrophobicity sites (lipids), based on Diaz et al. (2008). Images were obtained with a BX51 (Olympus, Japan) fluorescence light microscope (FLM). Observation settings were Ex365-370/B400/LP421 and Ex530-550/B570/LP591 for blue (DAPI) and red (Nile Red) channels, respectively. Merged images were obtained using ImageJ (National Institutes of Health, USA) package software.

\subsection{Analytical methods}

Sodium oleate powder salt (Riedel-de Haën/Sigma-Aldrich; 82\% C18:1/LCFA) was selected as LCFA substrate model due to its high solubility and its major presence on fatty wastewaters (Hwu et al., 1998). Analytical grade powder bentonite $\left(\mathrm{Al}_{2} \mathrm{O}_{3}\right.$ $4 \mathrm{SiO}_{2} \mathrm{H}_{2} \mathrm{O}$, Sigma-Aldrich) was selected as the synthetic adsorbent.

Total solids (TS), volatile solids (VS), volatile suspended solids (VSS) and pH were determined according to Standard Methods (APHA, 1995). Biogas and methane $\left(\mathrm{CH}_{4}\right)$ production was monitored by pressure transducer and gas chromatography techniques (FID and TCD), as described elsewhere (Angelidaki et al., 2009). Volatile fatty acids (VFA)-acetate $(\mathrm{Ac})$, propionate (Pro), iso and n-butyrate $(\mathrm{Bu})$ and iso and $n$-valerate $(\mathrm{Va})$ were determined after sample acidification with a CP-3800 gas chromatograph (Varian, USA), fitted with Tecknokroma TRB-FFAP capillary column (30 $\mathrm{m} \times 0.32 \mathrm{~mm} \times 0.25 \mu \mathrm{m})$ and FID detection (Palatsi et al., 2009). Long chain fatty acids (LCFA) - laurate (C12:0), myristate (C14:0), palmitate (C16:0), palmitoleate (C16:1), stearate (C18:0) and oleate (C18:1) - were determined as fatty acids methyl esters (FAME), based on direct LCFA methilationextraction procedure, with a CP-3800 gas chromatograph (Varian, USA), fitted with the capillary column Varian CP-Sil 88 $(50 \mathrm{~m} \times 0.25 \mathrm{~mm} \times 0.2 \mu \mathrm{m})$ and a FID detector, according to Palatsi et al. (2009). Obtained experimental samples were centrifuged (4500 rpm $10 \mathrm{~min}$ ), to differentiate between solid and liquid phase LCFA content (LCFA $\mathrm{S}_{\mathrm{S}}$ or $\mathrm{LCFA}_{\mathrm{L}}$, respectively).

\section{Results and discussion}

\subsection{LCFA adsorption isotherms on bentonite and granular sludge}

Bentonite has been considered a good adsorbent for organic species because of its high specific surface area, high porosity and surface activity. Scanning electron microscopy (SEM) and FT-IR spectrometric analysis evidenced the porous structure of the clay mineral and the possible interaction of LCFA molecules with the silanol $\left(\mathrm{SiO}_{2}\right)$ groups of bentonite (Demirbas et al., 2006). A Langmuir model was fitted against the experimental data and the obtained parameters were compared with the literature (Fig. 1). The obtained oleate maximum sorptivity value $\left(C_{\max }\right)$ on sludge-A was $373.78 \mathrm{mg}_{\mathrm{C} 18: 1 \text { adsorbed }} \mathrm{g}^{-1}$ TSadsorbent and the equilibrium constant $(\mathrm{K})$ was $1.7 \cdot 10^{-3} \mathrm{~L} \mathrm{mg}^{-1}{ }_{\mathrm{C} 18: 1 \text { soluble. }}$ These isotherm parameters were lower than those previously reported by Hwu et al. (1998), using a Freundlich isotherm model and thermally inactivated granular sludge. With respect to bentonite, the estimated $C_{\max }$ and $K$ values were $901.76 \mathrm{mg}_{\mathrm{C} 18: 1 a d s o r b e d} \mathrm{~g}^{-1}$ TSadsorbent and 1.23 $10^{-2} \mathrm{~L} \mathrm{mg}^{-1}$ C18:1soluble, respectively, which evidenced the relatively high adsorption capacity of the clay based mineral sorbent compared with biomass (sludge-A). These values were comparable to those obtained by Mouneimne et al. (2004) with bentonite suspensions and solid fatty wastes.

Assuming that adsorption can be described as a physical phenomenon dependent on the sorbent surface and sorbate concentration (Ning et al., 1996; Hwu et al., 1998), the higher specific surface area of clay minerals like bentonite (Raposo et al., 2004) in relation to the anaerobic granular sludge (further reported), explains the higher adsorption capacity of the former. These results show that bentonite outcompetes granular biomass in terms of sorptive capacity towards LCFA and, thus, its addition as a synthetic adsorbent in anaerobic digesters might influence dynamics of LCFA-adsorptioninhibition process.

\subsection{LCFA inhibitory concentration}

LCFA degradation rates by sludge- $\mathrm{A}$ and sludge-B were estimated, according to Material and Methods section, using the initial slope of the specific methane production rate at different initial LCFA concentrations. Exponential decay curves were fitted to the obtained degradation rates (Fig. 2).

A concentration of $0.5 \mathrm{~g}_{\mathrm{C} 18: 1} \mathrm{~L}^{-1}$ (aprox. $1.5 \mathrm{~g}_{\mathrm{COD}} \mathrm{L}^{-1}$ ) caused a decrease on the methane production rate higher than $50 \%$ in both sludges (sludge-A and sludge-B), according to Fig. 2. This value was selected as the reference oleate concentration in subsequent batch experiments (Table 1). It is interesting to observe that sludge- $B$ displayed a higher degradation capacity of oleate in relation to sludge-A, at least up to concentrations of $1 g_{C 18: 1} \mathrm{~L}^{-1}$ (Fig. 2). The different resistances of sludge-A and sludge-B to C18:1 inhibition will be discussed later, considering the results of biomass characterization (granules morphology, methanogenic activity and molecular profiling).

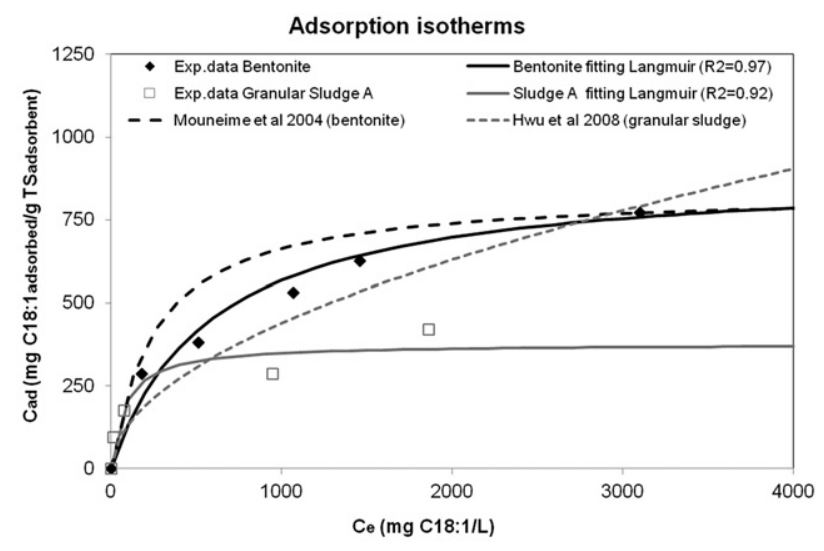

Fig. 1 - Estimated adsorption isotherms, using a Lagmuir isotherm model, for bentonite and inactivated sludge-A, and comparison with available literature values. Markers represent experimental data while lines represent data fitting to isotherm models. Coefficients of determination for data fitting $\left(R^{2}\right)$ are also indicated in the figure legend. 


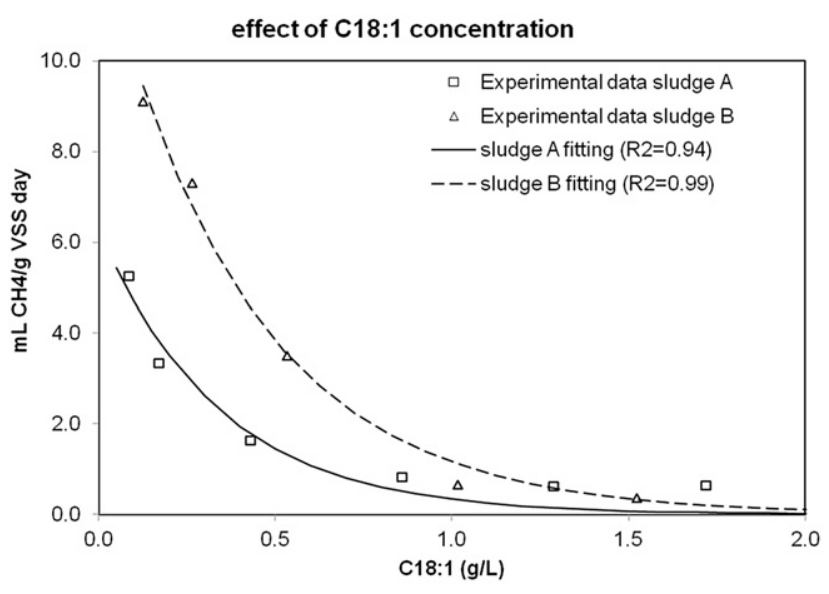

Fig. 2 - Effect of tested initial LCFA (C18:1) concentration (expressed as gc18:1 $\mathrm{L}^{-1}$ ) on the initial specific methane production rate $\left(\mathrm{mL}_{\mathrm{CH} 4} \mathrm{~g}^{-1}\right.$ vss $\left.\mathrm{d}^{-1}\right)$ of granular sludge-A and sludge-B. Markers represent experimental values while lines represent the fitting to an exponential decay curve. Coefficients of determination for data fitting $\left(R^{2}\right)$ are also indicated in the figure legend.

\subsection{Influence of the adsorptive process on LCFA inhibition}

Based on the previous results (adsorption isotherms and LCFA inhibitory concentration determination) different experiments were tested to study the effect of adsorptive process on LCFA inhibition and to quantify the LCFA adsorptioninhibitory effect by applying bentonite additions, as described previously in the Materials and Methods section (Table 1).

\subsubsection{Addition of bentonite prior or after LCFA inhibition (E1 and E2)}

The time course evolution of the LCFA $A_{S}$ and LCFA $A_{L}$ uptake, acetate transient accumulation, and methane production were monitored in E1 and E2, and showed in Fig. 3.

Considering that the oleate pulse was added from an aqueous stock solution, it was assumed that this LCFA was exclusively contained in the liquid phase (Fig. $3 b$ and $d$ ). The adsorption of LCFA from the liquid media to solid phase was quite fast in all treatments, including the control vials $(\mathrm{Ca})$ with no bentonite (Fig. 3a and c). Oleate uptake from the solid phase was followed by a clear accumulation of palmitate, primarily on the solid phase as well, as shown in Fig. 3c. No significant amounts of stearate nor palmitoleate were detected in liquid or solid phase samples (data not shown), which is consistent with the hypothesis of hydrogenation of unsaturated LCFA prior to the $\beta$-oxidation process (Lalman and Bagley, 2001).

The metabolism of LCFA resulted in a transient accumulation of acetate in the medium (Fig. 3e), which lasted until the complete degradation of palmitic acid. No significant amounts of other VFA intermediates (valerate, butyrate or propionate) were detected (data not shown), which is in agreement with others studies (Cavaleiro et al., 2009). The inhibition caused by the LCFA pulse also resulted in an immediate halt on methane production. However, this process was reversible as methane formation resumed after 30-35 days (Fig. 3f), when the remaining LCFA were completely depleted (Fig. $3 a$ and c).

No significant differences were observed in LCFA degradation, accumulation of acetate, and methane production, between bentonite ( $\mathrm{Ta} \_1$ ) and control $(\mathrm{Ca})$ vials in experiments E1 (Fig. 3), indicating that bentonite had little effect on preventing or modifying LCFA inhibition. A possible explanation for this unexpected phenomenon in E1 is the potential interaction between bentonite and biomass prior to the oleate pulse (4 days contact, Table 1). Clay minerals, like bentonite, have been largely used as support materials for the growth of anaerobic biofilms, due to their biomass adsorption capacity (Arnaiz et al., 2006). Furthermore, the spatial distribution and probability of bentonite-LCFA or biomass-LCFA adsorption occurrence, which is a function of LCFA concentration and particle density $\left(0.5\right.$ g Bentonite $\mathrm{L}^{-1}$ vs 5 gvssbiomass $\left.\mathrm{L}^{-1}\right)$, might have played an important role in the results. Mouneimne et al. (2004) considered this factor in the calculation of the adsorption isotherms for multiple species systems (biomass-clay mineralLCFA). Consequently, if biomass was attached to bentonite particles prior to LCFA pulse, the preventing effect expected in experiment E1 might have been severely hampered as the free adsorption sites available for LCFA in bentonite surface might have experienced a strong reduction (see scheme $a$ in Fig. 4).

On the other hand, relatively few differences were observed in the LCFA degradation profile and methane production rates, between bentonite ( $\mathrm{Ta}$ _2) and control vials (Ca) in the experiment E2, which resulted in a slightly faster acetate consumption and methane production rate (Fig. 3). If it is assumed that LCFA $\beta$-oxidation process was performed over the granule cell wall surface (only $\mathrm{Ac}$ and $\mathrm{H}_{2}$ delivered to the media, but not other LCFA intermediates), the addition of bentonite would affect only the initially (day +2 , Table 1 ) added LCFA concentration not yet adsorbed onto biomass (low according to Fig. 3). Consequently, the recovering effect of E2 would be poor (see scheme $b$ in Fig. 4).

In order to confirm that the measured accumulation of palmitic acid on the solid phase (LCFAs) is effectively adsorbed onto the granule surface (no $\beta$-oxidation intermediates delivered to the media) causing biomass inhibition, rather than just precipitating in the bulk media, granules from the control $(\mathrm{Ca})$ and blank vials $(B L a)$ were taken at day +10 , when most of the oleate had already been consumed and maximum palmitate levels were detected in the solid phase (Fig. 3c). Granules from $\mathrm{Ca}$ (incubations with biomass and oleate) and BLa (only biomass for endogenous activity), vials were sectioned, stained with DAPI-Nile Red, and examined under fluorescent light microscopy (FLM). Fig. 5 shows an example of the appearance under FLM of BLa (Fig. $5 \mathrm{a}-\mathrm{C}$ ) and $\mathrm{Ca}$ (Fig. $5 \mathrm{~d}-\mathrm{f}$ ) stained sections.

Nile Red is a hydrophobicity indicator but with this stain it is not possible to differentiate between the natural phospholipids of the cell membrane and the adsorbed LCFA (Diaz et al., 2008). Yet, the more intense Nile Red signal observed in the outer layer of the $\mathrm{Ca}$ granules (white arrow in Fig. 5f) in relation to the BLa further supports the fact that palmitate formed upon the metabolism of oleate is adsorbed on the granule surface, with the subsequent potential implications in membrane transport limitations or in other LCFA inhibitory effect. 


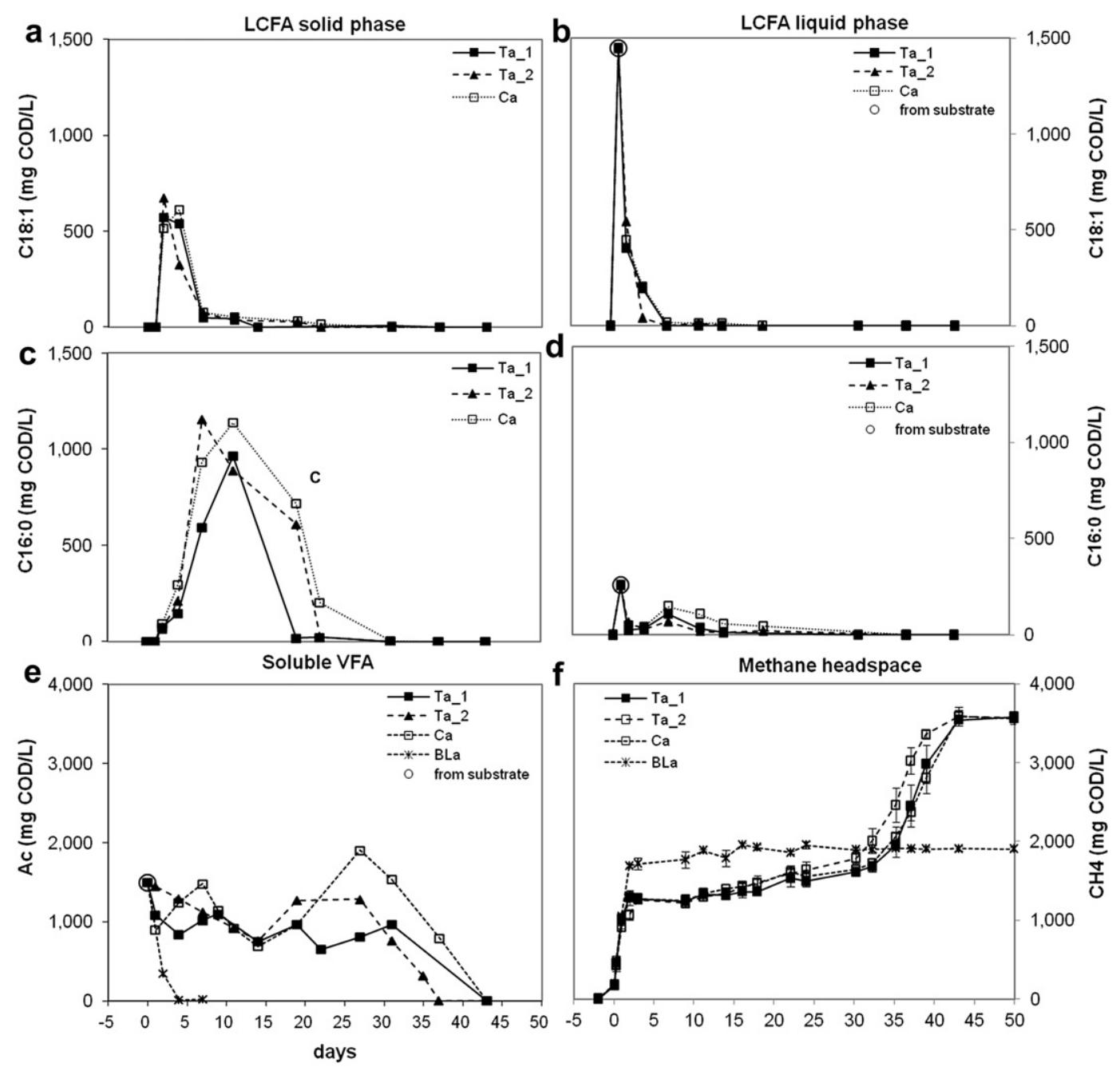

Fig. 3 - Comparison between E1 and E2 batch tests in terms of LCFA concentration in the solid phase (a and c) and in the liquid phase ( $b$ and d), acetate profile $(e)$ and methane formation $(f)$, for bentonite $\left(T_{A_{1} 1}\right.$ or $\left.T_{A_{2} 2}\right)$, control $\left(C_{A}\right)$ and blank $\left(B L_{A}\right)$ vials. All parameters are expressed in COD equivalent concentration units $\left(\mathrm{mg}_{\mathrm{COD}} \mathrm{L}^{-1}\right)$. The circles indicate the initial estimated concentration from LCFA pulse added into the vials.

\subsubsection{Addition of bentonite for LCFA capturing (E3)}

To confirm the implications of LCFA adsorption over process inhibition, a different new experiment (E3) was designed with sludge-B. In this case, bentonite was also incubated with

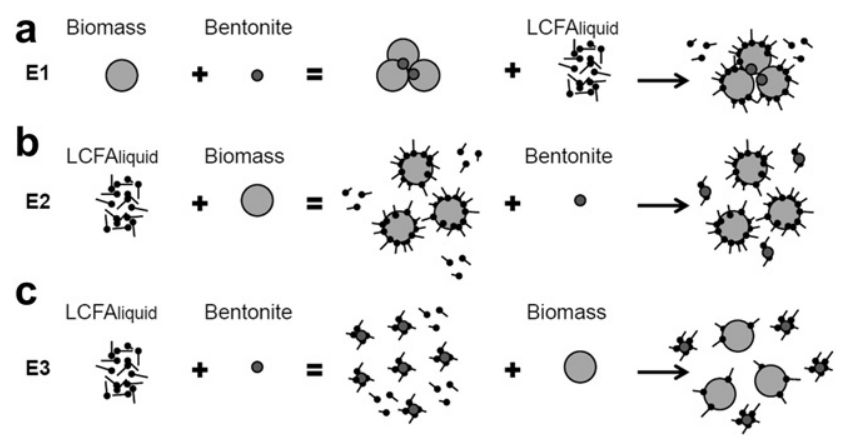

Fig. 4 - Scheme of the bentonite addition effect onto LCFA adsorption-inhibition process in E1, E2 and E3 experiments. oleate during 4 days prior to biomass addition (Table 1), in order to promote LCFA-bentonite adsorption or LCFA capturing for the enhanced protection of biomass from LCFA adsorption-inhibition. A higher content of adsorbent ( 5 gbentonite $\mathrm{L}^{-1}$ ) was added to have a more even biomass/ bentonite particle distribution ratio, as previously reported by Mouneimne et al. (2004). The time course evolution of the LCFA $_{S}$ and LCFA $A_{L}$ uptake, acetate transient accumulation, and methane production were monitored in E3, according to Fig. 6. The plot scales were maintained to that of the previous experiments (Fig. 3), in order to facilitate the direct comparison of the obtained results.

Since in E3 oleate was incubated during 4 days in a buffered medium with and without bentonite (Table 1), at the time of biomass addition (day 0 ) it was considered that all oleate was solubilized in $\mathrm{Cb}$ vials and adsorbed on $\mathrm{Tb}$ vials (Fig. $6 \mathrm{a}$ and $\mathrm{b}$ ). From the evolution of the oleate biodegradation pattern, clear differences were observed among treatments. Oleate biodegradation rates were higher when bentonite was added (Fig. 6a). A similar positive effect has 

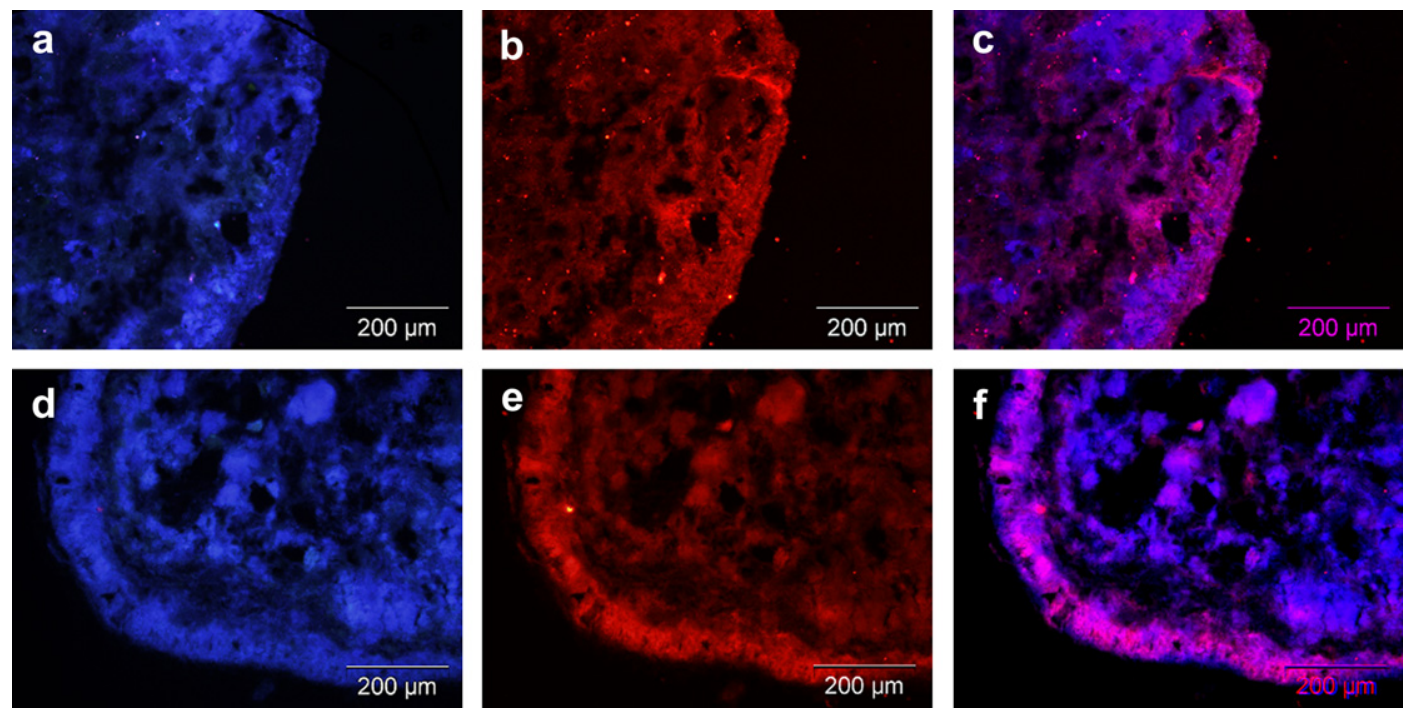

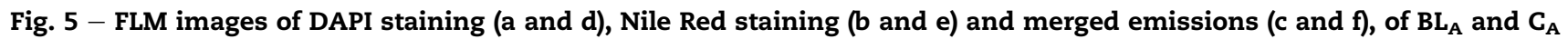
sectioned granules, respectively. (For interpretation of the references to colour in this figure legend, the reader is referred to the web version of this article.)

been described on sepiolite addition during anaerobic degradation of oleate (Cavaleiro et al., 2010). This phenomenon was then claimed to be the result of a decrease in the LCFA inhibitory effect because of the physical adsorption, but also to an improved metabolite transfer between acetogens and methanogens due to the higher proximity between those groups promoted by biofilm formation. This effect was not observed in the experiment E1, where biomass-bentonite adsorption was promoted (Fig. 3). Furthermore, in the experiment E3, oleate degradation did not produce the expected accumulation of palmitate in the solid phase, neither in the treatment vials nor in the controls (Fig. 6c), which points to the fact that sludge-B was probably more adapted to the metabolism of LCFA, as already indicated by the comparatively higher oleate biodegradation rate (Fig. 2). Cavaleiro et al. (2009) reported transient palmitate accumulation in reactors fed with oleate-based influents but, because of biomass adaptation, palmitate was not longer detected after two or three cycles of LCFA feeding. To clarify these aspects further biomass (sludge-A and sludge-B) characterization (granule morphology, methanogenic activity and bacterial community structure) was performed and further discussed in the next paragraphs, to explain their different LCFA biodegradation patterns. It must be noticed as well that sludge-B consisted of fresh granules collected from an operative UASB reactor from a fruit juice processing industry and, despite the preliminary starvation step, it still conserved a relatively high residual organic matter when compared to sludge-A (BLb vs BLa, methane production in Figs. 3 and 6). The presence of easily biodegradable co-substrates, such as glucose and cysteine, which are likely to be present in higher amounts on sludge- $B$, has been found to enhance the LCFA degradation rates (Kuang et al., 2006). Despite the intrinsic differences on the assayed sludges, the LCFA adsorptive action of bentonite in experiment E3, capturing LCFA, confirmed the implications of the LCFA-adsorptive process onto biomass, and confirms the adsorbent addition to be a reliable approach to improve the process robustness, by intervening on the kinetics of the LCFA adsorption and biological inhibition process (Fig. 4c). In particular, the acetate accumulation was prevented (Fig. 6e) and methane production was improved (Fig. 6f) upon bentonite addition. A Gompertz equation (Eq. (2)) was fitted to the methane production profile on both, treatment $(\mathrm{Tb})$ and control $(\mathrm{Cb})$ vials. as described in Fig. 6f. For an equivalent estimated $P_{\max }$ in $\mathrm{Cb}$ and $\mathrm{Tb}$ vials $\left(2569.4 \pm 106.6\right.$ and $2445.6 \pm 32.9 \mathrm{mg} \mathrm{COD}_{\mathrm{CH}_{4}} \mathrm{~L}^{-1}$, respectively), the lag phase for bentonite vials $(\mathrm{Tb})$ was significantly decreased from $6.2 \pm 0.8$ to $3.0 \pm 0.7$ days $(51.3 \%)$ whilst the maximum methane production rate was improved, from $130.5 \pm 12.2$ to $187.1 \pm 10.3 \mathrm{mg} \mathrm{COD} \mathrm{CH}_{4} \mathrm{~L}^{-1}$ day $^{-1}$ (43.3\%). Thus, it can be concluded that the LCFA-adsorptive process partially explain the LCFA inhibition process (nutrient transport limitation) with a clear effect on the overall degradation process, but there are still some initial inhibitory or toxic effect (cell or membrane damage) that must be also considered. Further complementary studies, which include mathematical modeling of the experimental data, are underway and will help to elucidate the relevance of specific factors that are associated to membrane damage.

\subsection{Influence of sludge characteristics on LCFA inhibition}

Considering that adsorption is a surface-related phenomenon, sludge specific area might be related to the LCFA inhibitory effect as well, as earlier proposed (Hwu et al., 1998). Therefore, the specific surface areas $\left(\mathrm{cm}^{2} \mathrm{~g}^{-1} \mathrm{vss}\right)$ of both granular sludges were estimated by image analysis (Table 2). The obtained values on the specific area of sludges$A$ and sludge-B were quite similar and did not explain the differences on the LCFA inhibitory effect. On the other hand, LCFA-degrading microorganisms are known to be proton 


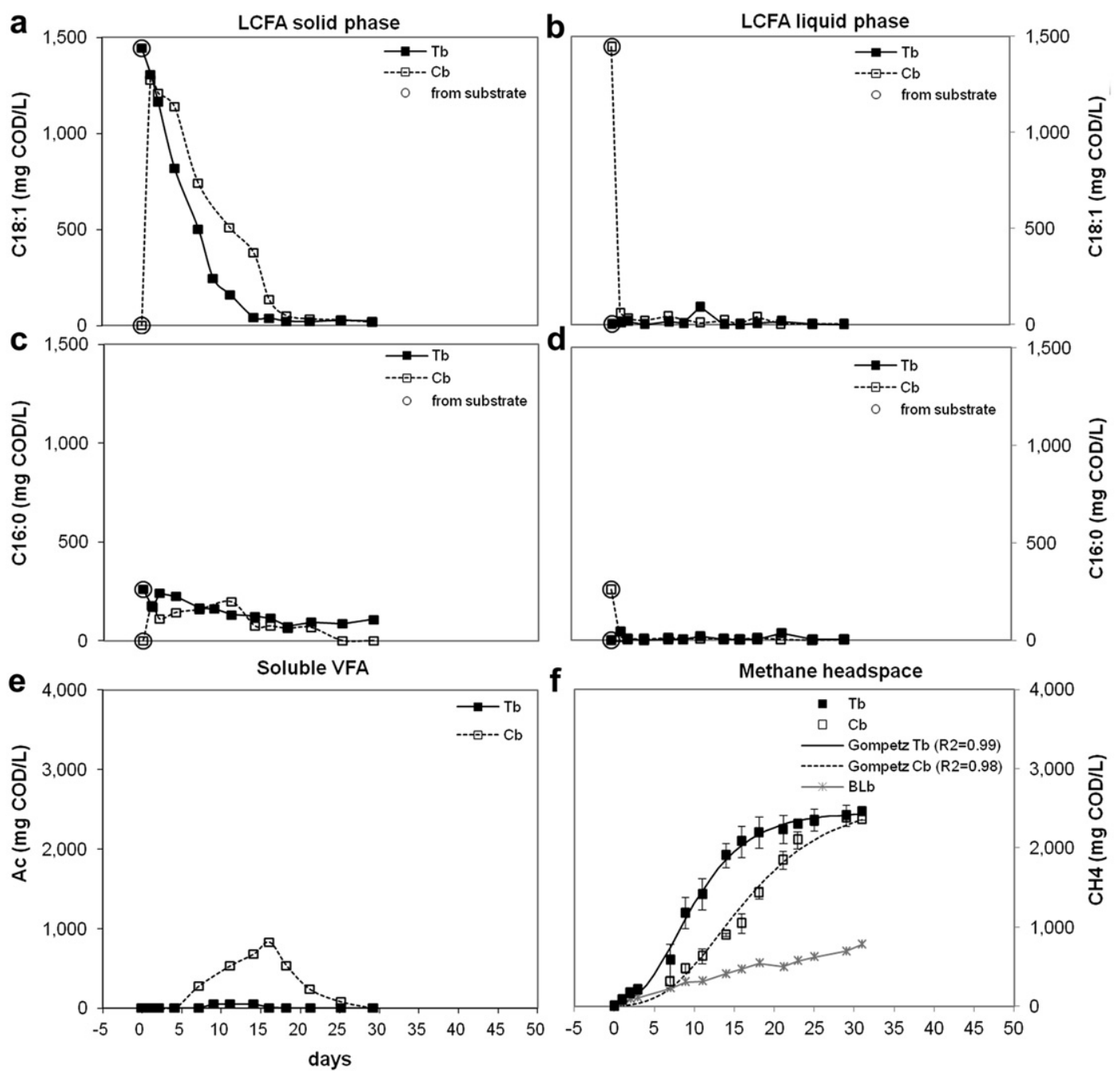

Fig. 6 - E3 batch tests in terms of LCFA concentration in the solid phase (a and c) and in the liquid phase (b and d), acetate profile (e) and methane formation (f), for bentonite $\left(T_{B}\right)$, control $\left(C_{B}\right)$ and blank $\left(B L_{B}\right)$ vials. All parameters are expressed in COD equivalent concentration units $\left(\mathrm{mg}_{\mathrm{COD}} \mathrm{L}^{-1}\right)$. The circles indicate the initial estimated concentration from LCFA pulse added into the vials.

reducing bacteria, which interact syntrophically with $\mathrm{H}_{2}$ utilizing and acetoclastic methanogens (Schink, 1997; Lalman and Bagley, 2001). Consequently, the balance between acetogenic bacteria and archaeal communities plays a central role in the LCFA metabolism, influencing the overall process rate (Pereira et al., 2002). Nevertheless, since sludge- $B$ had a lower methanogenic activity (both acetoclastic and hydrogenotrophic activity) than sludge- $\mathrm{A}$, it is not possible to conclude that differences concerning LCFA biomass tolerance are directly related to the methanogenic activity (Table 2).

Acetogenic and/or $\beta$-oxidizing bacteria can also influence sludge behavior in relation to LCFA tolerance and metabolism. A considerable increase in the $\beta$-oxidative activity of anaerobic sludge has been observed upon LCFA pulses (Pereira et al., 2005; Palatsi et al., 2010). Significant differences in the microbial community structure of bacterial populations from initial biomass samples (sludge-A and sludgeB) were observed upon DGGE profiling of PCR amplified
Table 2 - Summary of granular biomass characterization (mean values and standard deviation).

\begin{tabular}{|c|c|c|}
\hline Parameter & Sludge-A & Sludge-B \\
\hline $\begin{array}{l}\text { Sludge biomass content } \\
\left(\text { gvss L }^{-1}\right)\end{array}$ & $8.81 \pm 0.13$ & $8.87 \pm 0.02$ \\
\hline $\begin{array}{l}\text { Mean size as equivalent } \\
\text { diameter }(\mathrm{mm})\end{array}$ & $1.96 \pm 0.72$ & $2.04 \pm 0.93$ \\
\hline $\begin{array}{l}\text { Specific surface area } \\
\left(\mathrm{cm}^{2} \mathrm{~g}^{-1} \mathrm{vss}\right)\end{array}$ & $620.50 \pm 41.57$ & $540.13 \pm 58.65$ \\
\hline $\begin{array}{l}\text { Hydrogenotrophic } \\
\qquad \mathrm{SMA}\left(\mathrm{mL}_{\mathrm{CH} 4} \mathrm{~g}^{-1} \mathrm{vss}^{-1}\right)\end{array}$ & $179.66 \pm 1.66$ & $88.26 \pm 9.09$ \\
\hline $\begin{array}{l}\text { Acetoclastic SMA } \\
\qquad\left(\mathrm{mL}_{\mathrm{CH} 4} \mathrm{~g}^{-1} \mathrm{vss}^{-1}\right)\end{array}$ & $128.93 \pm 14.81$ & $69.69 \pm 1.97$ \\
\hline $\begin{array}{l}\text { C18:1 initial content } \\
\left(\mu \mathrm{g} \mathrm{g}^{-1} \mathrm{TS}_{\text {biomass }}{ }^{\mathrm{a}}\right)\end{array}$ & $<$ d.l & $10.5 \pm 0.7$ \\
\hline $\begin{array}{l}\text { C16:0 initial content } \\
\left(\mu \mathrm{g} \mathrm{g}^{-1} \mathrm{TS}_{\text {biomass }}{ }^{2}\right)\end{array}$ & $16.5 \pm 2.1$ & $105.0 \pm 2.8$ \\
\hline
\end{tabular}




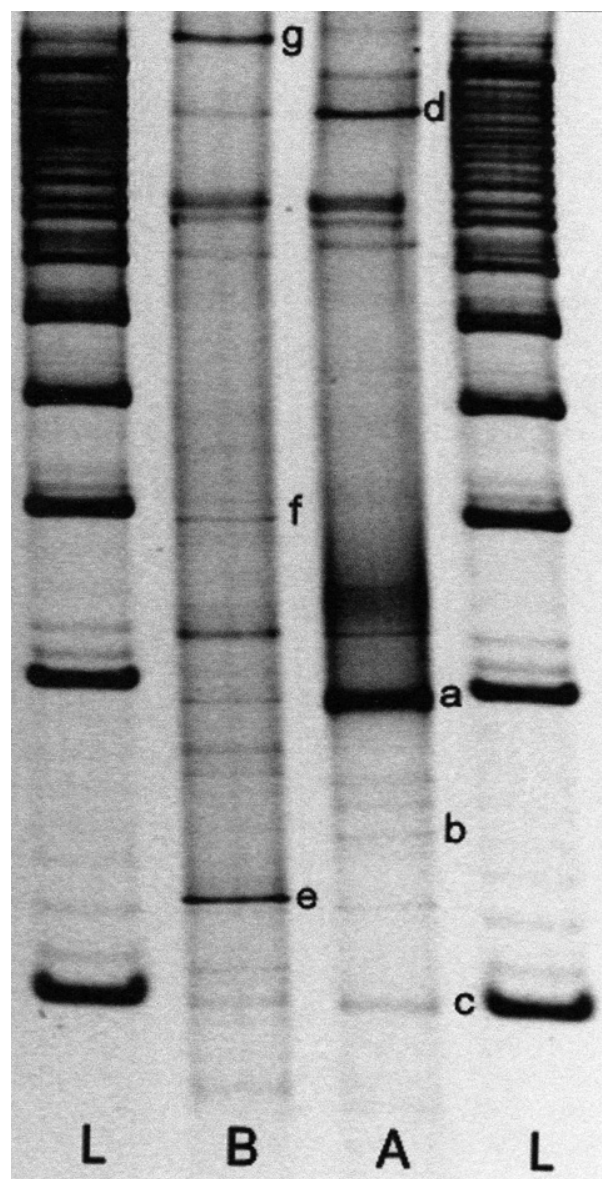

Fig. 7 - DGGE profiles of eubacterial 16S rDNA amplified from sludge-A and sludge-B. A standard ladder (L) has been used at both gel ends in order to check the DNA migration homogeneity. Successfully excised and sequenced bands have been named with lower-case letters. bacterial 16S rDNA ribotypes (Fig. 7). Up to 7 bands from the obtained profiles were successfully excised, reamplified and subsequently sequenced (Table 3). BLAST sequence comparisons against the NCBI genomic database resulted in close matches with uncultured ribotypes in most of cases, previously described in anaerobic granular reactors (Narihiro et al., 2009; Riviere et al., 2009). Several phylogenetic groups were identified, mainly related with fermenting bacteria and acetate or propionate oxidative microorganisms, but none of them was directly related to specific LCFA degrading bacteria. Considering the origin of the tested sludges, from industrial plants where lipids might only be present in residual amounts, the absence of bacterial species related to LCFA metabolism among the dominant fraction of the bacterial community is thus not surprising. Consequently, the initial number of bacteria responsible for LCFA degradation may not be high enough for yielding visible bands in a DGGE profile. Other molecular high throughput sequencing techniques, such as pyrosequencing, might give a deeper insight in relation to the presence and biodiversity of $\beta$-oxidizing bacteria. Nevertheless, the obtained results clearly reveal that the origin of the biomass is relevant to the LCFA metabolism. Sludge-A was obtained from a brewing industry, where its wastewaters are expected to be free of lipids. Conversely, sludge-B was obtained from a fruit juice facility, and the wastewater could have been in contact with higher lipid content from fruit peels or press liquor wastes. This fact would be in agreement with the analysis of the initial LCFA profile performed on both sludges (Table 2), in which a significantly higher amount of LCFA was found in sludge-B compared to sludge-A. Further complementary studies, which include mathematical modeling of the experimental data, are underway and will help to elucidate the relevance of the specific factors that are associated to the biomass.

Table 3 - DGGE bands: designations and accession numbers for the band sequences and levels of similarity to related organisms.

\begin{tabular}{|c|c|c|c|c|}
\hline Band & Accession no & $\begin{array}{l}{ }^{\mathrm{a}} \text { Closest organism in GenBank } \\
\text { database (access no.) GenBank } \\
\text { closest cultured/type strain (access no) }\end{array}$ & Similarity \% & ${ }^{\mathrm{b}}$ Phylogenetic group \\
\hline \multirow[t]{2}{*}{ Band $a$} & HM1000129 & Uncultured (AB266993) & 100.0 & Geobacter \\
\hline & & Geobacter hephaestius strain VeEG4 ${ }^{\mathrm{TC}}$ (AY737507) & 97.8 & \\
\hline \multirow[t]{2}{*}{ Band $b$} & HM1000130 & Uncultured (CU923168) & 100.0 & Anaerolineaceae \\
\hline & & Levilinea saccharolytica strain KIBI-1 ${ }^{\text {TC }}$ (AB109439) & 92.1 & \\
\hline \multirow[t]{2}{*}{ Band c } & HM1000131 & Uncultured (DQ443992) & 99.8 & Synergistaceae \\
\hline & & Aminomonas paucivorans stain GLU-3 (AF072581) & 89.9 & \\
\hline \multirow[t]{2}{*}{ Band $d$} & HM1000132 & Uncultured (CU918694) & 100.0 & Petrimonas sulfuriphila \\
\hline & & Petrimonas sulfuriphila stain BN3 (AY570690) & 100.0 & \\
\hline \multirow[t]{2}{*}{ Band $e$} & HM1000133 & Uncultured (EU937734) & 99.3 & Brooklawnia \\
\hline & & Brooklawnia cerclae strain BL-34 ${ }^{\text {TC }}$ (DQ196625) & 97.3 & \\
\hline \multirow[t]{2}{*}{ Band $f$} & HM1000134 & Uncultured (AB175367) & 100.0 & Bacterioides \\
\hline & & Cellulophaga tyrosinoxydans strain EM41 ${ }^{\mathrm{TC}}$ (EU443205) & 91.1 & \\
\hline \multirow[t]{2}{*}{ Band $g$} & HM1000135 & Uncultured (AB267007) & 98.0 & Paludibacter \\
\hline & & Paludibacter propionicigenes strain WB4 ${ }^{\mathrm{TC}}$ (AB078842) & 91.5 & \\
\hline
\end{tabular}




\section{Conclusions}

Batch incubations of methanogenic biomass from two different origins have clearly shown the inhibitory effect of oleate at concentrations above $0.5 \mathrm{~g}_{\mathrm{C} 18: 1} \mathrm{~L}^{-1}$. Nevertheless, this process was reversible and methanogenic activity recovered, showing that partial $\beta$-oxidation was a non-limiting step. Palmitate was confirmed as the main intermediate in less adapted biomass and the main LCFA inhibitory species. Solid and liquid LCFA characterization and fluorescence staining microscopy inspection of the biomass, performed once all oleate was consumed from the liquid phase, demonstrated that palmitate was mostly adsorbed on granules surface.

Oleate adsorption over anaerobic granular sludge and over bentonite was characterized by means of Langmuir isotherms, which revealed the higher adsorption capacity of bentonite. Batch experiments designed to quantify the importance of the LCFA adsorption process on biological inhibition, by means of bentonite addition, proved that the protection of granule surface from LCFA-rich streams is a reliable approach to improve the system robustness, by affecting LCFA-biomass adsorption dynamics. Nevertheless, there is part of the inhibitory effect that still must be related with a LCFA toxic effect. Yet, biomass adaptation to LCFA is equally important for the anaerobic treatment of lipids.

\section{Acknowledgments}

This work was funded by the Spanish Ministry of Science and Innovation (projects ENE 2007-65850 and CTM 2010-18212), and was partially supported by a grand from the Department of Universities, Research and Media Society of Catalonia Government (BE-DGR 2008 BE1 00261). We would like to thank Lucia Neves, Ana Nicolau, Madalena Vieira, and Ana Julia Cavaleiro, from University of Minho, for their assistance in microscopic observations and analytical methods. We also thank Miriam Guivernau (IRTA) for assistance in the PCRDGGE profiling and ribotype sequencing. We are also grateful to David Bedoya (MWH) and Francesc Prenafeta (IRTA) for the revision and critical reading of the manuscript.

\section{R E F E R E N C E S}

Altschul, S.F., Gish, W., Miller, W., Myers, E.W., Lipman, D.J., 1990. Basic local alignment search tool. Journal Molecular Biology 215, 403-410.

Angelidaki, I., Alves, M., Bolzonella, D., Borzacconi, L., Campos, L., Guwy, A., Jenicek, P., Kalyuzhnui, S., van Lier, J., 2009. Defining the biomethane potential (BMP) of solid organic wastes and energy crops: a proposed protocol for batch assays. Water Science and Technology 59 (5), 927-934.

APHA, AWWA, WEF, 1995. Standard Methods for the Examination of Water and Wastewater, nineteenth ed. American Public Health Association, American Water Works Association, Water Environment Federation, Washington DC, USA.

Arnaiz, C., Gutierrez, J.C., Lebrato, J., 2006. Support material selection for anaerobic fluidized bed reactor by phospholipid analysis. Biochemical Engineering Journal 27, 240-245.
Batstone, D.J., Keller, J., Blackall, L.L., 2004. The influence of substrate kinetics on the microbial community structure in granular anaerobic biomass. Water Research 38, 1390-1404.

Battimelli, A., Torrijos, M., Moletta, R., Delgenès, J.P., 2010. Slaughterhouse fatty waste saponification to increase biogás yield. Bioresource Technology 100, 3388-3393.

Cavaleiro, A.J., Salvador, A.F., Alves, J.I., Alves, M., 2009. Continuous high rate anaerobic treatment of oleica cid based wastewater is possible after a step feeding start-up. Environmental Science and Technology 43, 2931-2936.

Cavaleiro, A.J., Sousa, D.Z., Alves, M.M., 2010. Methane production from oleate: assessing the bioaugmentation potential of Syntrophomonas zehnderi. Water Research 44, 4940-4947.

Demirbas, A., Sari, A., Isildak, O., 2006. Adsorption thermodynamics of stearic acid onto bentonite. Journal of Hazardous Materials B135, 226-231.

Desbois, A.P., Smith, V.J., 2010. Antibacterial free fatty acids: activities, mechanisms of action and biotechnological potential. Applied Microbiology and Biotechnology 85, 1629-1642.

Diaz, G., Melis, M., Batetta, B., Angius, F., Falchi, A.M., 2008. Hydrophobic characterization of intracellular lipids in situ by Nile red red/yellow emission ratio. Micron 39, 819-824.

Galbraith, H., Miller, T.B., 1973. Effect of long chain fatty acids on bacterial respiration and amino acid uptake. Journal of Applied Microbiology 36 (4), 659-675.

Hwu, C.-S., Tseng, S.-K., Yuan, C.-Y., Kulik, Z., Lettinga, G., 1998. Biosorption of long-chain fatty acids in UASB treatment process. Water Research 32 (5), 1571-1579.

Kuang, Y., Pullammanappallil, P., Lepesteur, M., Ho, G.-E., 2006. Recovery of oleate-inhibited anaerobic digestion by addition of simple substrates. Journal of Chemical Technology \& Biotechnology 81, 1057-1063.

Lalman, J.A., Bagley, D.M., 2001. Anaerobic degradation and methanogenic inhibitory effects of oleic and stearic acids. Waster Research 35, 2975-2983.

Mouneimne, A.H., Carrère, H., Bernet, J.P., Delgenès, J.P., 2004. Effect of the addition of bentonite on the anaerobic biodegradability of solid fatty wastes. Environmental Technology 25 (4), 459-469.

Narihiro, T., Terada, T., Kikuchi, K., Iguchi, A., Ikeda, M., Yamauchi, T., Shiraishi, K., Kamagata, Y., Nakamura, K., Sekiguchi, Y., 2009. Comparative analysis of bacterial and archaeal communities in methanogenic sludge granules from upflow anaerobic sludge blanket reactors treating various food-processing, high-strength organic wastewaters. Microbes Environment 24 (2), 88-96.

Ning, J., Kennedy, K., Fernandes, L., 1996. Biosorption of 2,4dichorophenol by live and chemically inactivated anaerobic granules. Water Research 30, 2039-2044.

Palatsi, J., Laureni, M., Andrés, M.V., Flotats, X., Nielsen, H.B., Angelidaki, I., 2009. Strategies for recovering inhibition caused by long chain fatty acids on anaerobic thermophilic biogas reactors. Bioresource Technology 100, 4588-4596.

Palatsi, J., Illa, J., Prenafeta-Boldú, F.X., Laureni, M., Fernandez, B. Angelidaki, K., Flotats, X., 2010. Long-chain fatty acids inhibition and adaptation process in anaerobic thermophilic digestión: batch tests, microbial community structure and mathematical modelling. Bioresource Technology 101, 2243-2251.

Pereira, M.A., Pires, O.C., Mota, M., Alves, M.M., 2002. Anaerobic degradation of oleic acid by suspended sludge: identification of palmitic acid as a key intermediate. Water Science and Technology 45 (10), 139-144.

Pereira, M.A., Roest, K., Stams, A.J.M., Akkermans, A.D.L., Amaral, A.L., Pons, M.-N., Ferreira, E.C., Mota, M., Alve, M.M., 2003. Image analysis, methanogenic activity measurements, and molecular biological techniques to monitor granula 
sludge from an EGSB reactor fed with oleic acid. Water Science and Technology 47 (5), 181-188.

Pereira, M.A., Pires, O.C., Mota, M., Alves, M.M., 2005. Anaerobic biodegradation of oleic and palmitic acids: evidence of mass transfer limitations caused by long chain fatty acids. Accumulation onto the anaerobic sludge. Biotechnology and Bioengineering 92 (1), 15-23.

Raposo, F., Borja, R., Sanchez, E., Martín, M.A., Martín, A., 2004. Performance and kinetic evaluation of anaerobic digestión of two-phase olive mill effluents in reactors with suspended and immobilized biomass. Water Research 38, 2017-2026.

Rinzema, A., Boone, M., van Knippenberg, K., Lettinga, G., 1994. Bactericidal effect of long chain fatty acids in anaerobic digestion. Water Environmental Research 66, 40-49.

Riviere, D., Desvignes, V., Pelletier, E., Chaussonnerie, S., Guermazi, S., Weissenbach, J., Li, T., Camacho, P., Sghir, A., 2009. Towards the definition of a core of microorganisms involved in anaerobic digestion of sludge. ISME Journal 3 (6), 700-714.
Schink, B., 1997. Energetics of syntrophic cooperation in methanogenic degradation. Microbiology Molecular Biology Review 61, 262-280.

Sousa, D.Z., Pereira, M.A., Stams, A.J.M., Alves, M.M., 2007. Microbial communities involved in anaerobic degradation of unsaturated or saturated long chain fatty acids (LCFA). Applied Environmental Microbiology 73 (4), 1054-1064.

Valladão, A.B.G., Torres, A.G., Freire, D.M.G., Cammarota, M.C., 2011. Profiles of fatty acids and triacylgylcerols and their influence on the anaerobic biodegradability of effluents from poultry slaughterhouse. Bioresource Technology 102 (14), 7043-7050.

Wang, Q., Garrity, G.M., Tiedje, J.M., Cole, J.R., 2007. Naïve Bayesian classifier for rapid assignment of rRNA sequences into the new bacterial taxonomy. Applied Environmental Microbiology 73 (16), 5261-5267.

Zheng, C.J., Yoo, J.-S., Lee, T.-G., Cho, H.-Y., Kim, Y.-H., Kim, W.-G., 2005. Fatty acid synthesis is a target for antibacterial activity of unsaturated fatty acids. FEBS Letters 579, 5157-5162. 